\title{
Decision making in double-pedicled DIEP and SIEA abdominal free flap breast reconstructions: an algorithmic approach and comprehensive classification
}

\author{
Charles M. Malata ${ }^{1,2 *}$ and Nicholas G. Rabey ${ }^{2,3}$ \\ ${ }^{1}$ Postgraduate Medical Institute, Faculty of Health Sciences, Anglia Ruskin University, Cambridge and Chelmsford, UK, \\ ${ }^{2}$ Cambridge Breast Unit, Plastic and Reconstructive Surgery Department, Cambridge University Hospitals NHS Foundation \\ Trust, Cambridge, UK, ${ }^{3}$ Department of Plastic and Reconstructive Surgery, Salisbury District Hospital, Salisbury, UK
}

OPEN ACCESS

Edited by:

Michel Saint-Cyr,

Mayo Clinic, USA

Reviewed by:

Furkan Erol Karabekmez,

Kecioren Training and Research

Hospital, Turkey

Sydney Ch'Ng,

Royal Prince Alfred Hospital, Australia

*Correspondence:

Charles M. Malata,

Addenbrooke's Hospital, Cambridge

University Hospitals NHS Foundation

Trust, Cambridge CB2 2QQ, UK

cmalata@hotmail.com

Specialty section:

This article was submitted to Reconstructive and Plastic Surgery,

a section of the

journal Frontiers in Surgery

Received: 19 May 2015 Accepted: 10 September 2015 Published: 26 October 2015

Citation:

Malata CM and Rabey NG (2015) Decision making in double-pedicled DIEP and SIEA abdominal free flap breast reconstructions: an algorithmic approach and comprehensive classification.

Front. Surg. 2:49.

doi: 10.3389/fsurg.2015.00049
Introduction: The deep inferior epigastric artery perforator free flap is the gold standard for autologous breast reconstruction. However, using a single vascular pedicle may not yield sufficient tissue in patients with midline scars or insufficient lower abdominal pannus. Double-pedicled free flaps overcome this problem using different vascular arrangements to harvest the entire lower abdominal flap. The literature is, however, sparse regarding technique selection. We therefore reviewed our experience in order to formulate an algorithm and comprehensive classification for this purpose.

Methods: All patients undergoing unilateral double-pedicled abdominal perforator free flap breast reconstruction (AFFBR) by a single surgeon (CMM) over 40 months were reviewed from a prospectively collected database.

Results: Of the 112 consecutive breast free flaps performed, 25 (22\%) utilised two vascular pedicles. The mean patient age was 45 years (range $=27-54$ ). All flaps, but one (which used the thoracodorsal system), were anastomosed to the internal mammary vessels using the rib-preservation technique. The surgical duration was $656 \mathrm{~min}$ (range $=468-690 \mathrm{~min}$ ). The median flap weight was $618 \mathrm{~g}$ (range $=432-1275 \mathrm{~g}$ ) and the mastectomy weight was $445 \mathrm{~g}$ (range $=220-896 \mathrm{~g}$ ). All flaps were successful and only three patients requested minor liposuction to reduce and reshape their reconstructed breasts.

Conclusion: Bipedicled free abdominal perforator flaps, employed in a fifth of all our AFFBRs, are a reliable and safe option for unilateral breast reconstruction. They, however, necessitate clear indications to justify the additional technical complexity and surgical duration. Our algorithm and comprehensive classification facilitate technique selection for the anastomotic permutations and successful execution of these operations.

Levels of evidence: Therapeutic level IV.

Keywords: Bipedicled free flaps, double-pedicle free flaps, stacked free flaps, breast reconstruction, abdominal free flaps, DIEP and SIEA breast free flaps, intra-flap and extra-flap microvascular anastomoses, rib sparing internal mammary vessel exposure 


\section{Introduction}

The free single-pedicled deep inferior epigastric artery perforator (DIEP) flap is the gold standard for autologous breast reconstruction. However, its harvest based on one vascular pedicle may not provide enough viable abdominal tissue in patients who are slim, nulliparous, post massive-weight loss, have midline abdominal scars, or possess minimal abdominal tissue with comparatively large breasts. Double-pedicled abdominal free flaps are designed to overcome this deficit by utilizing most of the lower abdominal tissue for unilateral breast reconstruction. While single-pedicled free TRAM flaps may perfuse more tissue than a single-pedicled DIEP flap they carry a higher donor site morbidity and do not consistently or reliably perfuse Hartrampf Zone 4, which is necessary to harvest a larger flap.

Bipedicled or double-pedicled abdominal perforator flaps are so-named because they are supplied by two anatomically distinct vascular pedicles, thereby increasing the total tissue volume with a Hartrampf Zone I type perfusion $(1,2)$. Harvesting the entire lower abdomen on two vascular pedicles was pioneered by Arnez and Scamp in 1992 using their bipedicled free TRAM flap design (3). Blondeel and Boecyx, however, were the first to apply this concept to free abdominal perforator flaps in their 1994 description of a DIEP flap (4). Several series have since shown the reliability of bipedicled free DIEP flaps (5-8). However, there are multiple flap configurations and arrangements of the vascular anastomoses (Table 1).

The blood supply of bipedicled free abdominal flaps may originate from the deep inferior epigastric arteries (DIEAs), superficial inferior epigastric arteries (SIEAs), DIEP perforators, or a combination of these. These options were first classified by Hamdi et al. according to the named vessel and vascular configuration employed (6). Various authors have since utilized similar or different anatomical vascular arrangements (5-8, $14,15)$. Hitherto there has, however, been no comprehensive classification. In general the anastomoses of the two pedicles

TABLE 1 | Published reports on the abdominal bipedicled flap for breast reconstruction.

\begin{tabular}{|c|c|c|c|c|}
\hline Study & $\begin{array}{l}\text { Number } \\
\text { of cases }\end{array}$ & Indications & $\begin{array}{l}\text { Flap tissue } \\
\text { arrangement }\end{array}$ & Vascular arrangements \\
\hline (4) & 1 & Midline abdominal scar & Single layer & $\begin{array}{l}\text { Primary DIEA to IMV } \\
\text { Secondary DIEA to inferior continuity of } \\
\text { primary DIEA }\end{array}$ \\
\hline (9) & 1 & $\begin{array}{l}\text { Large contralateral breast, } \\
\text { midline abdominal scar }\end{array}$ & Stacked & $\begin{array}{l}\text { Primary DIEA to subscapular artery } \\
\text { Secondary DIEA to inferior continuity of } \\
\text { primary DIEA }\end{array}$ \\
\hline (6) & 16 & $\begin{array}{l}\text { Previous liposuction (19\%), } \\
\text { abdominal scars (31\%), } \\
\text { insufficient tissue volume } \\
(50 \%)\end{array}$ & $\begin{array}{l}\text { Single layer, folded } \\
\text { if required }\end{array}$ & $\begin{array}{l}\text { DIEA/DIEA flaps (43.8\%) } \\
\text { DIEA/SIEA flaps (43.8\%) } \\
\text { DIEA/perforator flaps (12.5\%) } \\
\text { All primary pedicle anastomosis to IMV, } \\
\text { secondary pedicle to primary DIEA ( } 81.3 \%) \text {, } \\
\text { secondary pedicle to TDAs (18.8\%) }\end{array}$ \\
\hline$(10)$ & 1 & Midline abdominal scar & Stacked & $\begin{array}{l}\text { Primary: DIEA to TDA } \\
\text { Secondary: SIEA to inferior continuity of DIEA }\end{array}$ \\
\hline (5) & 14 & $\begin{array}{l}\text { Thin abdominal wall }(21 \%) \text {, } \\
\text { large contralateral breast } \\
\text { (C cup or above } 57 \%)\end{array}$ & Single layer & $\begin{array}{l}\text { DIEA/DIEA (42.9\%) } \\
\text { DIEA/MS-TRAM (57.1\%) } \\
\text { Donor vessels } \\
\text { - } \quad \text { TDA and serratus }(21.4 \%) \\
\text { - } \quad \text { TDA and IMV }(71.4 \%) \\
\text { - IMVs anterograde and retrograde }(7.1 \%)\end{array}$ \\
\hline
\end{tabular}

(11)

(7)

\section{5}

96

Infraumbilical vertical abdominal scar (100\%)

Previous abdominal scars (31.9\%) including midline abdominal scars (25.7\%)

(12)

(13)
55
Large contralateral breast

Insufficient abdominal volume
Single layer

Single layer

Folded

Folded and stacked
Primary DIEA pedicle to IMV. Secondary DIEA pedicle to superior continuity of primary pedicle

All used IMVs for primary DIEA pedicle anastomoses. For secondary DIEA pedicle

- Superior continuity: $43.7 \%$

- Inferior continuity end-to-end: $30.2 \%$

- Inferior continuity artery end-to-side: $24.0 \%$

- Extra-flap anterograde/retrograde: $2 \%$

DIEA/DIEA to IMV extra-flap anterograde/ retrograde.

Primary DIEA pedicle (superficial) to IMVs, secondary DIEA pedicle (deep) intra-flap anastomosis to primary pedicle
Complications

Nil

Re-exploration needing vein anastomosis and graft

- Scar correction (25\%)

- Donor wound dehiscence (19\%)

- Fat necrosis $(6 \%)$

- Lipofilling (6\%)

Nil

- Cellulitis (7\%)

- Delayed healing (7\%)

- Hypertrophic scar (7\%)

- Local recurrence (7\%)

- Contralateral mastopexy $14 \%$

- Abdominal bulge (7\%)

- Blood transfusion (21\%)

Minor fat necrosis $(40 \%)$

- Total Flap Loss - 1.8\%

- Partial flap loss $-0.9 \%$

- Re-exploration-6.2\%

- Breast fat necrosis - 10.6\%

- Abd wound infection: $2.7 \%$

- Abdominal bulge $(0.9 \%)$

Nil

Hematoma (5.4\%) 
may take the form of an intraflap ("in-series") arrangement as described by Hamdi et al., an extraflap (“in-parallel”) arrangement or a combined intraflap-extraflap arrangement using the internal mammary vessels (IMVs) in combination with the thoracodorsal or other vessels $(9,10,16,17)$. In the extraflap arrangement the two pedicles are independently anastomosed to the IMVs for the primary flap and to the thoracodorsal vessels (TDVs) or retrograde IMVs or other vessels for the secondary flap $(6,10)$. The combined intraflap-extraflap arrangement employs an arterial anastomosis of the secondary flap pedicle to an intraflap site and the venous anastomosis to an extraflap site or vice versa.

Despite the proven efficacy of abdominal bipedicled free flaps (Table 1), the literature is sparse regarding the choice of vessel configuration and flap inset. We therefore deemed it useful to present an algorithm for technique selection and propose a comprehensive classification. This was based on a single surgeon's experience with 25 consecutive bipedicled free flap breast reconstructions. We predict our algorithm will optimize patient outcomes for this complex microvascular procedure.

\section{Patients and Methods}

All patients undergoing unilateral bipedicled abdominal free flap breast reconstruction were identified from a prospective database of microsurgical procedures carried out at Cambridge University Hospital, UK. All procedures were performed over a 40-month period from November 2010 to March 2014 by a single surgeon (CMM).

Data collected included indications, microvascular anastomotic details and flap outcomes. In addition, patient demographics, breast size, previous adjuvant therapy, co-morbidities, inter-rib space type and width were recorded. Collation of the patient demographics, BMI, mastectomy weights, flap weights, inter-rib space distances, surgery duration and flap ischemia times was carried out using Microsoft Excel ${ }^{\mathrm{TM}}$ Software.

\section{Flap Selection: Bipedicled DIEP Versus Unipedicled DIEP}

Patients requiring autologous tissue reconstruction based on their need for adjuvant radiotherapy or refusal to accept implant-based reconstructions were considered for abdominal tissue reconstruction. The decision to perform a bipedicled flap rather than a standard unipedicled flap was based on clinical assessment of the donor abdomen by the senior author (CMM). This was based on an estimate that three quarters of the lower abdominal tissue (which can be reliably perfused by one set of deep inferior epigastric vessels) would not be sufficient to reconstruct the required breast size. This took into account increasing the abdominal tissue available by schamfering the harvest while enabling safe closure of the donor site. An underlying assumption was (the nearly universally held view) that DIEP flaps are preferable to free TRAM flaps in view of the donor site morbidity. No intraoperative tests, such as clamping of the one set of perforators, were undertaken to determine the horizontal extent of the flap perfusion.

\section{Flap Harvest}

All patients were marked up the day before surgery. The perforators were located using an $8 \mathrm{MHz}$ Doppler probe. Later in the series, all patients $(n=15)$ underwent CT angiography of the abdominal wall vessels (DIEP and SIEA). The flap was raised in a standard fashion from lateral to medial then inferior to superior and then superior to inferior carefully identifying and preserving the perforators. The SIEA pedicle was utilized if the artery was deemed suitable with good pulsatility and a diameter of $>1 \mathrm{~mm}$ (3). The dissection end point of the SIEA pedicle was at the femoral vessel junction, beyond the artery bifurcation. This is important in ensuring a large enough artery and minimizing discrepancy with the recipient arteries.

For DIEP flaps, the perforators were exposed by carefully incising the rectus sheath with a size 15 blade without excising any of the sheath. The perforator course was then followed through the muscle up to the main pedicle carefully ligating the side branches. At least $2 \mathrm{~cm}$ of vessel was preserved at the superior continuity and inferior continuity of the DIE vascular pedicles in case these were needed for intraflap anastomoses.

The pedicle was dissected toward its origin from the external iliac vessels aiming beyond the confluence of the venae commitantes. This was repeated on the opposite side.

The side with the best perforators became the primary flap and anastomosed anterograde to the internal mammary vessels. In the entire series, one flap was divided into two hemiflaps and rotated $90^{\circ}$ to lie vertically adjacent to each other in the breast pocket (in order to increase its width).

\section{Recipient Vessel Preparation}

This utilized the total rib-preservation technique detailed in the author's previous publication (15). The IMVs were exposed in the second intercostal space (ICS) without cartilage sacrifice but removal of the intercostal muscles. Occasionally, the third ICS was exposed in order to try and identify veins proximal to any confluence.

\section{Rectus Sheath Closure}

When required, the opening(s) in the rectus sheath was closed using looped " 0 " nylon over-and-over continuous sutures in two layers. If the flap configuration utilized two DIE vascular pedicles repair of the two incisions in the sheaths was performed simultaneously by two surgeons to avoid unequal distribution of tension and facilitate closure of the second side. Mesh reinforcement was not used in any of the patients.

\section{Vessel Selection for Anastomoses}

This is detailed in the algorithm (vide infra).

\section{Results}

Over the 40-month period, a total of 112 free abdominal flaps were performed in 98 consecutive patients by one surgeon. 25 (22\%) had a bipedicled vascular configuration (Table 2). The mean patient age was 45 years $(27-54)$. The median BMI was $23.7 \mathrm{~kg} / \mathrm{m}^{2}$ (20.2-28.7). The bra cup sizes were 2 As, 3 Bs, 9 Cs, 7 Ds, 2 Es, and 2 Gs. The indications for surgery were (alone or in combination): inadequate abdominal tissue for one breast, 
TABLE 2 | Bipedicled abdominal free flap patient summary.

\begin{tabular}{|c|c|c|c|c|c|c|c|c|c|c|}
\hline $\begin{array}{l}\text { Case } \\
\text { no. }\end{array}$ & Age & BMI & Cup size & $\begin{array}{c}\text { Immediate (I)/ } \\
\text { delayed (D) }\end{array}$ & $\begin{array}{c}\text { Flap } \\
\text { configuration }\end{array}$ & $\begin{array}{l}\text { Ischemia } \\
\text { duration } \\
\text { (min) }\end{array}$ & $\begin{array}{l}\text { Surgery } \\
\text { duration } \\
\text { (min) }\end{array}$ & $\begin{array}{l}\text { Rib space } \\
\text { width (mm) }\end{array}$ & $\begin{array}{c}\text { Adjuvant } \\
\text { postoperative } \\
\text { radiotherapy }\end{array}$ & Complications \\
\hline 1 & 26 & 24.9 & $\begin{array}{l}34 \mathrm{~B} / \mathrm{C} \\
32 \mathrm{DD}\end{array}$ & I & $\begin{array}{l}\text { DIEA/DIEA } \\
\text { extraflap }\end{array}$ & 104 & 770 & 14.5 & No & \\
\hline 2 & 43 & 23.4 & $34 \mathrm{~B} / \mathrm{C}$ & I & III b & 98 & 744 & 20 & Yes & \\
\hline 3 & 38 & 23.1 & $32 \mathrm{~A} / \mathrm{B}$ & I & $\| \mathrm{b}$ & 83 & 780 & 24 & Yes & $\begin{array}{l}\text { Requested } \\
\text { liposuction }\end{array}$ \\
\hline 4 & 45 & 26 & $36 \mathrm{~B}$ & I & III a & 91 & 690 & 19 & Yes & \\
\hline 5 & 51 & 25.3 & $34 \mathrm{C}$ & I & $\begin{array}{l}\text { DIEA/DIEA } \\
\text { extraflap }\end{array}$ & 90 & 600 & 26 & No & \\
\hline 6 & 43 & 24 & $36 B / C$ & Salvage & III a & 110 & 790 & 21 & No & \\
\hline 7 & 43 & 24.7 & 34D & I & $\begin{array}{l}\text { DIEA/DIEA } \\
\text { extraflap }\end{array}$ & 65 & 600 & 26 & No & \\
\hline 8 & 46 & 20.2 & $36 C$ & I & $\| \mathrm{b}$ & 115 & 748 & 27 & No & $\begin{array}{l}\text { Requested } \\
\text { liposuction }\end{array}$ \\
\hline 9 & 50 & 22.8 & $34 B / C$ & I & $\begin{array}{l}\text { DIEA/DIEA } \\
\text { extraflap }\end{array}$ & 81 & 716 & 15 & No & \\
\hline 10 & 42 & 22.9 & $36 D$ & I & $\| \mathrm{a}$ & 82 & 690 & 15 & Yes & $\begin{array}{c}\text { Small area fat } \\
\text { necrosis }\end{array}$ \\
\hline 11 & 47 & 20.3 & $34 C$ & I & III a & 190 & 675 & 16 & Yes & $\begin{array}{l}\text { Requested } \\
\text { liposuction }\end{array}$ \\
\hline 12 & 40 & 22.5 & $36 B$ & I & $\begin{array}{l}\text { DIEA/DIEA } \\
\text { extraflap }\end{array}$ & 76 & 654 & 19 & Yes & $\begin{array}{l}\text { Abdominal wound } \\
\text { dehiscence }\end{array}$ \\
\hline 13 & 46 & 23.9 & 36B & I & $\begin{array}{l}\text { DIEA/DIEA } \\
\text { extraflap }\end{array}$ & 125 & 650 & 23 & Yes & \\
\hline 14 & 44 & 21.3 & $32 D$ & I & III b & 101 & 554 & 20 & Yes & \\
\hline 15 & 54 & 23.9 & $32 D$ & I & $\begin{array}{l}\text { DIEA/DIEA } \\
\text { extraflap }\end{array}$ & 106 & 572 & 26 & Yes & \\
\hline 16 & 53 & 23.4 & $34 D$ & I & $\begin{array}{l}\text { DIEA/DIEA } \\
\text { extraflap }\end{array}$ & 130 & 647 & 26 & No & \\
\hline 17 & 53 & 25.2 & $32 \mathrm{G}$ & I & $\begin{array}{l}\text { DIEP-DIEA } \\
\text { extraflap }\end{array}$ & 157 & 554 & 17 & Yes & \\
\hline 18 & 46 & 23 & $32 E$ & 1 & $\begin{array}{l}\text { SIEA/SIEA } \\
\text { extraflap }\end{array}$ & 118 & 622 & 20 & Yes & \\
\hline 19 & 34 & 18.7 & 34D & 1 & $\begin{array}{c}\text { DIEP-DIEP } \\
\text { extraflap }\end{array}$ & 129 & 693 & 14 & Yes & \\
\hline 20 & 48 & 28.8 & $34 \mathrm{E}$ & Delayed & $\| \mathrm{b}$ & 55 & 535 & 14 & Yes. Pre-op & \\
\hline 21 & 50 & 26.2 & $32 D$ & 1 & $\begin{array}{l}\text { DIEA-DIEA } \\
\text { extraflap }\end{array}$ & 87 & 670 & 24 & No & \\
\hline 22 & 45 & 24.3 & 36AA & Delayed & $\begin{array}{l}\text { DIEA-DIEA } \\
\text { extraflap }\end{array}$ & 107 & 582 & 22 & Yes & \\
\hline 23 & 48 & 25 & $32 \mathrm{G}$ & I & $\begin{array}{l}\text { DIEA-DIEA } \\
\text { extraflap }\end{array}$ & 182 & 691 & 18 & No & \\
\hline 24 & 49 & 23.5 & $36 C$ & I & $\begin{array}{l}\text { DIEP-SIEA } \\
\text { extraflap }\end{array}$ & 92 & 702 & 19 & No & \\
\hline 25 & 26 & 26 & $36 C$ & Salvage & $\begin{array}{c}\text { DIEP-DIEP } \\
\text { extraflap }\end{array}$ & 60 & 468 & 22 & Yes. Pre-op & \\
\hline
\end{tabular}

refusal of implant-based reconstruction, small breast volume or planned postoperative radiotherapy (Figures 1-3). Two patients had failed prosthetic reconstructions salvaged with bipedicled free flaps. No patients had midline abdominal scars.

The median mastectomy weight was $445 \mathrm{~g}$ (range $=220-896$ ) with a median flap weight of $618 \mathrm{~g}$ (range $=432-1275)$. The microvascular anastomoses used (Table 3) were DIEA/DIEA extraflap in 15 patients (Figures 1 and 4), DIEA/DIEA intraflap in four (two superior and two inferior "continuities") (Figure 2), DIEA/SIEA extraflap in one, DIEA/SIEA intraflap in four (two superior and two inferior "continuities") (Figure 5) and SIEA/ SIEA in one patient (Figure 3).

The median surgery duration was $670 \mathrm{~min}(468-790)$ with flap ischemia time of $103 \mathrm{~min}$ (24-190). Twenty-one reconstructions 

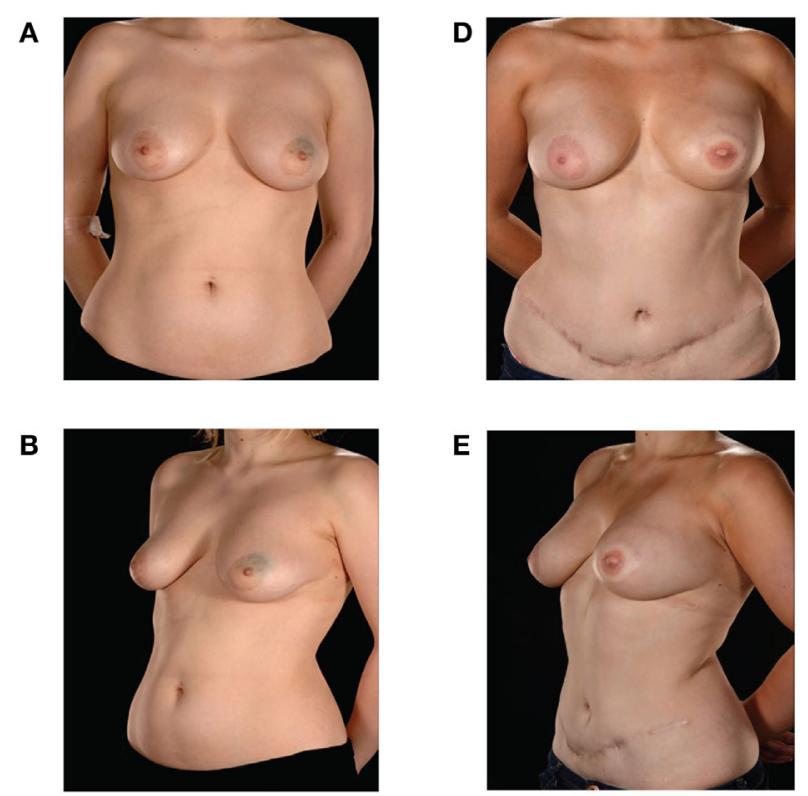

C

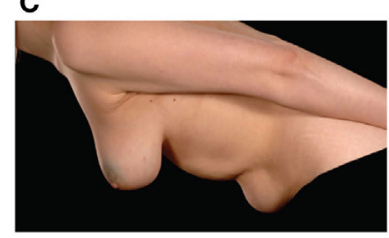

$\mathbf{E}$

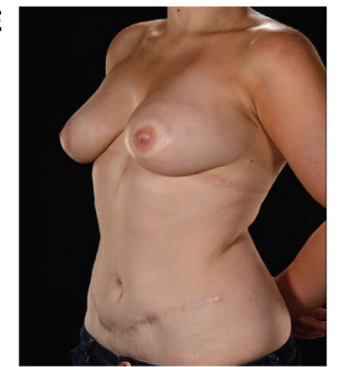

$\mathbf{F}$

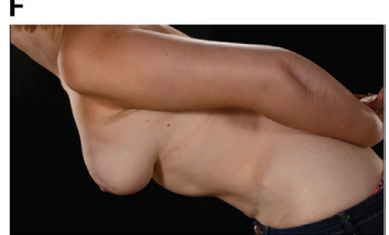

FIGURE 1 | Preoperative (A-C) and postoperative (D-F) appearances of a 26-year-old patient with size $D$ cup breasts. She received an extraflap configuration DIEP-DIEP bipedicled free flap breast reconstruction.

were immediate, two were delayed and two were salvage (tertiary). All patients used the total ipsilateral rib-preservation method of IMV harvest. The second ICS was used in 17 patients and both second and third spaces in 8 patients. The widths for the ICSs ranged from 14 to $27 \mathrm{~mm}$ for the second space and 11 to $25 \mathrm{~mm}$ for the third.

The arterial anastomoses were all performed end-to-end using

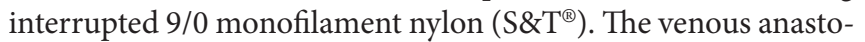
moses were undertaken with a venous coupler in 45 anastomoses (83\%) and with $9 / 0 \mathrm{MFN}$ continuous suture in eight (17\%). The vein of the second flap was anastomosed to the bifurcated anterograde IMV vein in 6 cases (24\%), its retrograde limb in 14 (56\%), intraflap superior continuity 5 (20\%), intraflap inferior continuity $3(12 \%)$ and to the thoracodorsal vein in 1 (4\%) (Table 4$)$. The intercostal perforators and the pectoral vein were not used. The secondary pedicle arterial anastomoses were the retrograde IM artery in 16 cases (64\%) with identical figures for the superior and inferior "continuities" and the TDVs. There were no anterograde internal mammary secondary pedicle arterial anastomoses [as these would have to be end-to-side (ETS) on the same IMA used as the recipient for the primary pedicle].

All flap reconstructions were successful with no partial flap losses and no re-explorations. One patient needed on-table revision of the primary arterial anastomosis whilst another two required venous anastomoses revision due to coupler device

A

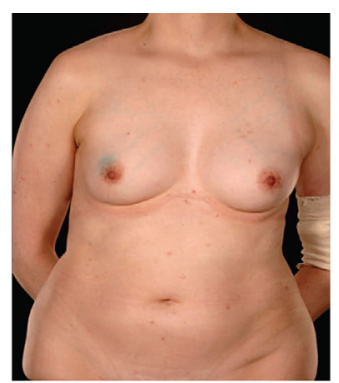

B

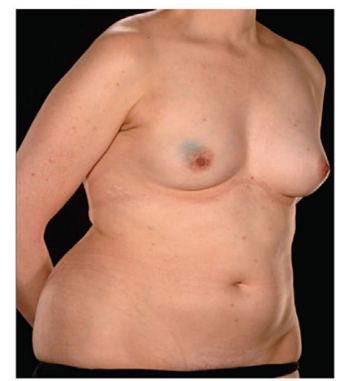

C

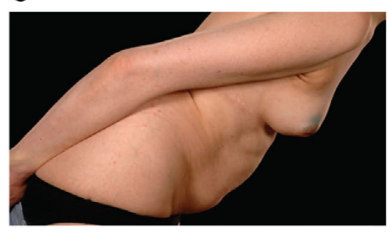

D
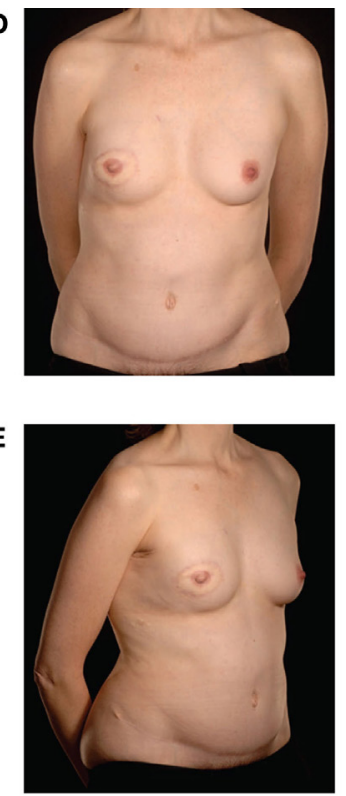

$\mathbf{F}$

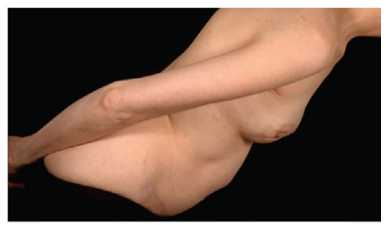

FIGURE 2 | Preoperative (A-C) and postoperative (D-F) appearances of a 43-year-old nulliparous patient with size $B$ cup breasts who required postoperative radiotherapy and refused to countenance the idea of an implant-based reconstruction. She underwent a Type Illb DIEP-DIEP bipedicled flap reconstruction.

malfunction. Where indicated $(n=14)$ the immediate reconstructions received adjuvant radiotherapy post-operatively without delay. One patient developed a $2-\mathrm{cm}$ area of fat necrosis laterally on the SIEA flap side and this was managed conservatively. Another patient experienced exacerbation of a pre-existing lower abdominal bulge currently being treated conservatively. She also had minor dehiscence of her abdominal incision possibly due to smoking history. There have been no complaints of herniation or symptomatic abdominal wall tightness after a median follow up of 18.5 months (1-40). Three patients requested liposuction to reshape their reconstructed breasts.

\section{Discussion}

Bipedicled free abdominal flaps widen the pool of patients who can benefit from the advantages of autologous tissue breast reconstruction. This series shows that the technique of transferring the entire lower abdominal flap on two vascular pedicles is reliable whilst being associated with minimal morbidity. The indications for double-pedicled flaps in the present series were usually a combination of factors which included the patient's body habitus (relative size of the breast versus the lower abdomen) and their preference for totally autologous reconstruction. This was 


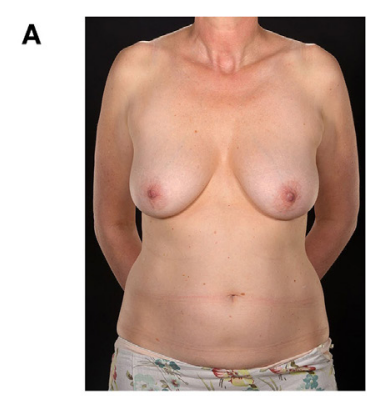

$\mathbf{B}$

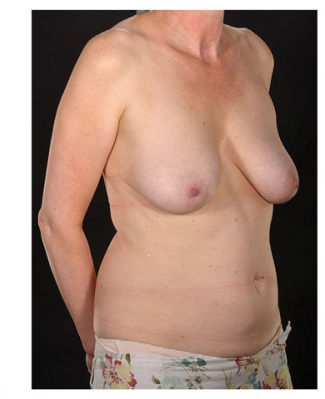

C

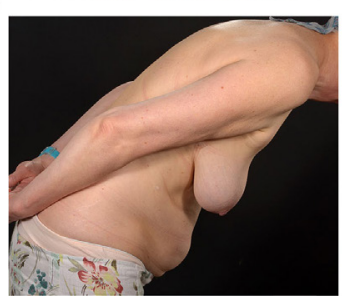

D

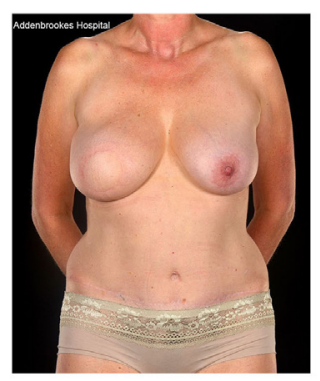

E

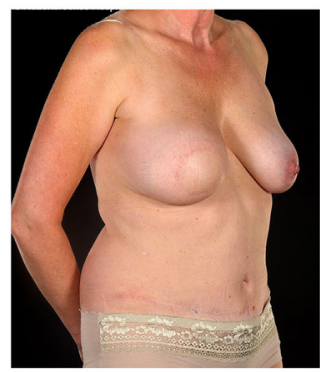

$\mathbf{F}$

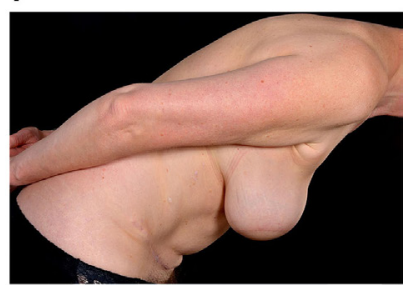

FIGURE 3 | Preoperative (A-C) and two-year postoperative (D-F) and post-radiation appearances of a 46-year-old nulliparous patient with large breasts (size E cup) and a relatively small abdomen. She underwent a Type 1 SIEA-SIEA double-pedicled free flap breast reconstruction at the time of her therapeutic mastectomy. She has hitherto declined nipple reconstruction.

TABLE 3 | Summary of the vessel constructs used in this bipedicled abdominal free flap series.

\begin{tabular}{lccc}
\hline Name of construct & DIEP/DIEP & DIEP/SIEA & SIEA/SIEA \\
\hline Inferior continuity & 2 & 2 & - \\
Superior continuity & 2 & 2 & - \\
Extraflap anastomoses & 15 & 1 & 1 \\
Totals & 19 & 5 & 1
\end{tabular}

especially when adjuvant radiotherapy was planned. The decision whether to undertake a unipedicled or bipedicled DIEP flap was a clinical one made preoperatively in the outpatient clinic.

Previous published series have discussed various options for the arrangement of transferred tissue and microvascular configurations (Table 1). There are four described flap arrangements once the abdominal tissue is transferred onto the chest wall (5-10, 14-17). In the "stacked" variety the flap is split into two and positioned one on top of the other. The "coned" variant contours the horizontally orientated flap to various degrees. In a third option the bipedicled flap is rotated $90^{\circ}$ to be vertical and "folded" over. This is useful for narrow breasts. The fourth type splits the flap into two, rotates each hemiflap $90^{\circ}$ toward each other then

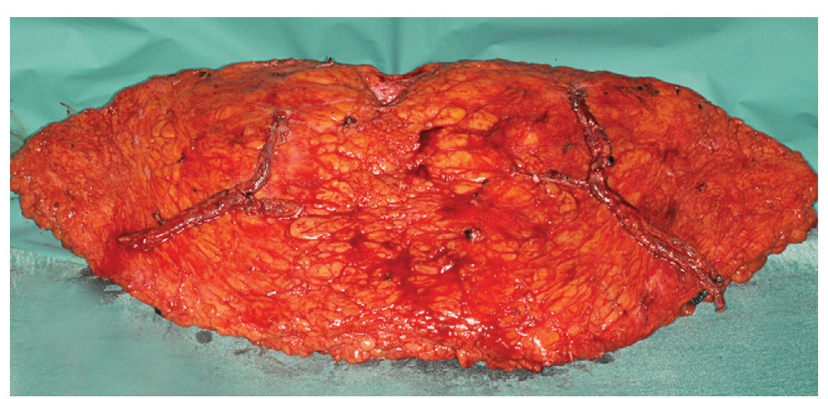

FIGURE 4 | An intraoperative photograph of a bipedicled DIEP-DIEP flap after harvest prior to micro-anastomoses. Each hemiflap is based on two perforators.

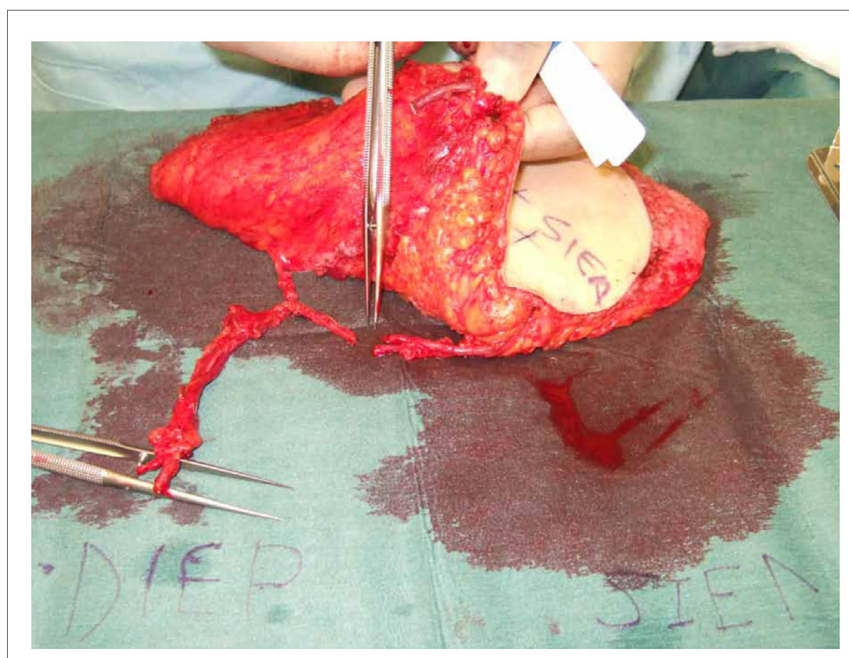

FIGURE 5 | An intraoperative photograph of a DIEP-SIEA showing the ease of anastomoses of the SIEA second pedicle to the superior continuity of the DIEP primary vascular pedicle.

TABLE 4 | Summary of recipients used for venous and arterial anastomoses for the secondary flap.

\begin{tabular}{lcc}
\hline Recipient vessels & Venous number (\%) & Arterial number (\%) \\
\hline Retrograde IM vessel & $11(44)$ & $16(64)$ \\
Anterograde IM vessel & $6(24)$ & $0(0)$ \\
Superior pedicle continuity & $5(20)$ & $5(20)$ \\
Inferior pedicle continuity & $3(12)$ & $3(12)$ \\
Thoracodorsal vessel & $1(4)$ & $1(4)$ \\
Intercostal perforator & $0(0)$ & $0(0)$ \\
Pectoral vein & $0(0)$ & $0(0)$ \\
\hline
\end{tabular}

arranges them vertically "adjacent" to each other. These arrangements are designed to maximize volume but must not be viewed in isolation from the microvascular anastomotic permutations.

The anastomoses for the second vascular pedicle can be performed intraflap, extraflap, or rarely both intraflap-extraflap (Table 4; Figure 6). The intraflap configurations consist of anastomosing the secondary vascular pedicle to branches of the primary flap's vascular pedicle as detailed by Hamdi et al. (Figure 7). 
In the extraflap arrangement the secondary flap's vessels are separately anastomosed retrogradely to the internal mammary vessels or anterogradely to the TDVs or other chest wall vessels (5-10, 14-17) (Table 1). Although all these articles report good outcomes, there is a wide variability in the microvascular configurations used. From our experience we have identified two points in the procedure when careful consideration of the arrangement to use for the microvascular anastomoses is critical. The first is the selection of pedicle design during flap harvest (Figure 8), and the second is the combination of recipient vessels for anastomoses (Figure 9), especially when an extraflap configuration for two pedicles is required. We have found that preoperative CT angiography can assist our vessel selection.

Intra-operatively we therefore make the following considerations. The superficial inferior epigastric (SIE) vessels are evaluated initially for pulsatility, size and location (Figure 8). This pedicle should be explored first because it is easier and quicker to dissect and gives less donor site morbidity. The SIEA vascular pedicle may provide good flap perfusion whilst avoiding trauma to the rectus abdominis muscle and fascia, such as that required for the raising of a DIE pedicle (3). However, occasionally the SIE vessels may have been injured in previous abdominal surgery, so care needs to be taken over their selection. If both arteries have a good caliber of $>1 \mathrm{~mm}$ and display good pulsatility and orientation, then they are determined to be adequate and a bilateral SIEA Hamdi type I flap can be fashioned. If not, then the DIEAs must be considered next.

In our experience the easier and faster-to-dissect lateral row perforators can be used preferentially as an adequate basis of the bipedicled DIEP flap as there is sufficient perfusion of Hartrampf zones IV or III across the flap midline. This is in contrast to the situation in a unipedicled DIEP free flap where the more centrally located medial row perforators are to be preferred. Usually the medial row perforators are larger than lateral row ones and single (medial row) perforator unilateral DIEP pedicles are commonplace. When based on the lateral row we prefer to use at least two perforators in unipedicled flaps to be assured of overall flap perfusion and especially venous drainage. However, if two DIEA pedicles are being used then one lateral row perforator on each side should be adequate.

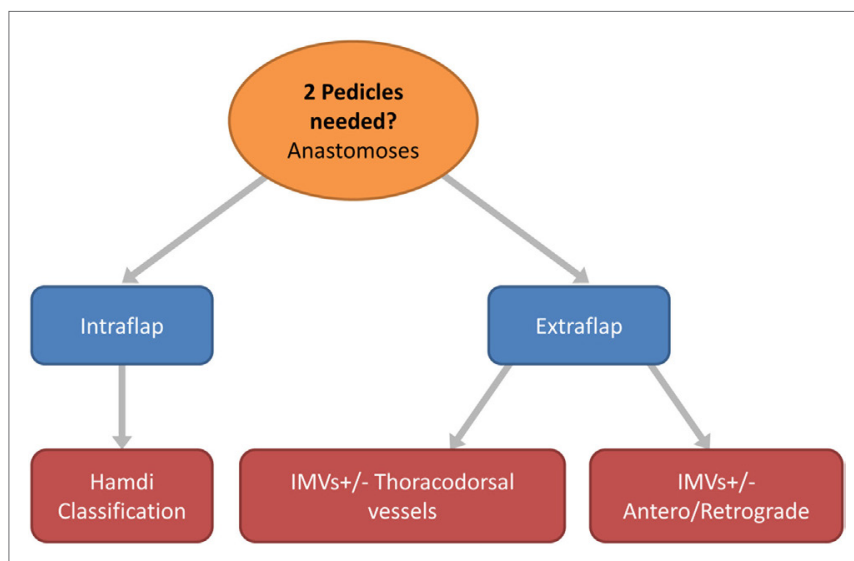

FIGURE 6 | Flow chart depicting the options in free flap vascular pedicle design for bipedicled microvascular flap anastomoses.
The next important stage is the evaluation of the superior and inferior "continuities" and branches of the DIE system (Figure 8; step 2). We have found that the superior "continuity" of the pedicle can be fragile, especially the venae comitantes, and should be assessed before the pedicle is divided as its vessels collapse post-division and become difficult to evaluate. The critical consideration here is the vein, which tends to be more friable due to its thinner wall. If both the artery and vein of the primary pedicle superior "continuation" have a sufficient caliber and quality, then a superior "continuity" intraflap anastomosis can be made with the secondary pedicle (Hamdi Type IIb or IIIb) (Figures 5 and 6). If not, the inferior continuity is considered, which usually supplies the medial row perforators. When basing the flap on lateral row perforators, the ligation of the division leading up to the medial perforators must leave an adequate "stump" for use in Hamdi type IIa and IIIa flap variations $(6,14)$. Rarely, an artery from the superior "continuity" can be used with a vein from the inferior "continuity" $(14,15)$ or vice versa. If these "continuities" are not suitable then the second pedicle must be anastomosed in an extraflap arrangement. We avoid the ETS intra-flap anastomoses described by $\mathrm{Xu}$ et al. because of the vagaries of this anastomotic type and the concern that it might thrombose due to turbulence at the anastomosis as a consequence of its close proximity to the primary flap anastomosis.

For the recipient vessel selection (Figure 9) all the patients in our series had their IMVs exposed using the senior surgeon's total rib-preservation technique (18). In the entire series the primary flap artery was anastomosed to the IMA in an anterograde fashion. The secondary flap artery was anastomosed to the retrograde IMA limb in $64 \%(16 / 25)$ of cases. This reflects the practical ease of a single recipient site and the well-documented adequate retrograde arterial flow $(19,20)$.

Selecting the appropriate vein for the second pedicle is another crucial step in ensuring pedicled free flap success. Using the same IMV recipients for both pedicles is beneficial because only one recipient site needs to be exposed and the position facilitates the flap inset and shaping. Ideally, two anterograde veins would be used as the recipient vessels to avoid any valves in the retrograde veins (21). We preferentially use the second ICS because of its numerous advantages (18). If the second space is small $(<20 \mathrm{~mm})$ we sometimes also expose the third space (Figure 9). This serves two purposes:

(a) It may expose the IMV venous confluence and thus provide the easier anterograde venous anastomoses. Often the vein confluence is just under the cranial edge of the third costal cartilage $(22,23)$.

(b) It lengthens the limbs of the vessels to be used for anterograde and retrograde anastomoses.

However, care must be taken when dissecting the vessels under the third rib cartilage. This is aided by the observation that there are no side branches of the IMVs directly under the cartilage where visibility would be difficult. The need for meticulous ligation of any tributaries at the superior and inferior aspects of the third costal cartilage is obvious. To facilitate the anastomoses, the third costal cartilage could be sacrificed as in the traditional method of IMV exposure, but we have not found this to be necessary in our series. 
Type I (SIEA-SIEA)

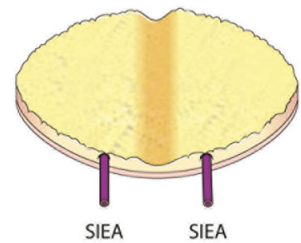

Type II (SIEA-DIEP)

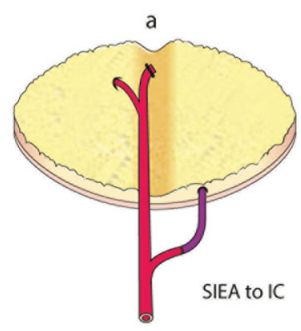

Type III (DEIP-DIEP)

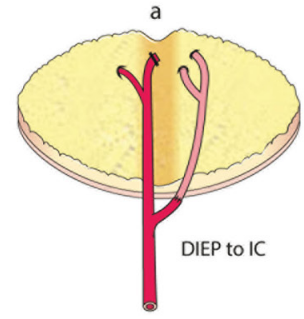

Type IV (DIEP-DIEP perforator)

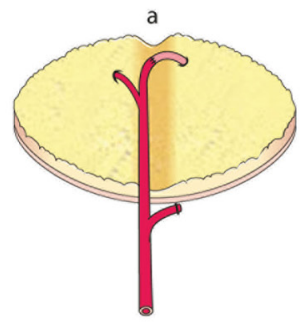

Key:

SIEA $=$ superficial inferior epigastric artery flap

SIEV = superficial inferior epigastric vein flap

DIEP $=$ deep inferior epigastric perforator flap

$\mathrm{IC}=$ inferior continuity

$\mathrm{SC}=$ superior continuity
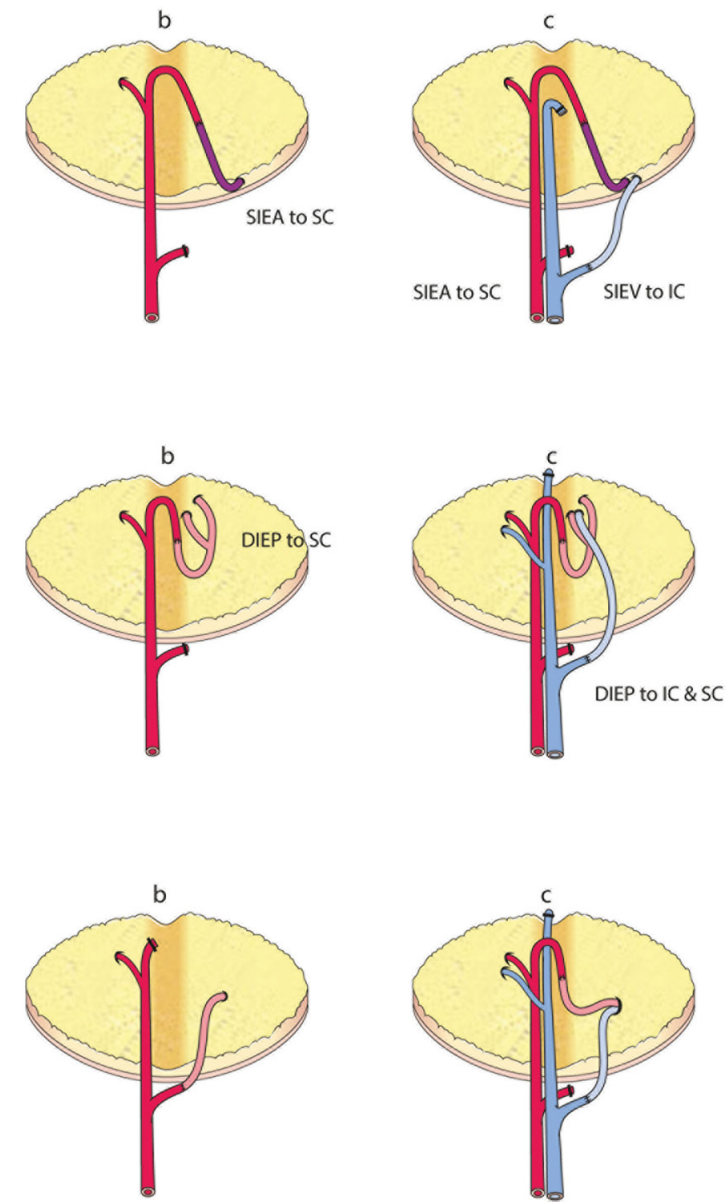

FIGURE 7 | Comprehensive classification of the variations for intraflap anastomoses in bipedicled abdominal free flaps (modified after Hamdi et al.).

If two anterograde IM veins are not available we resort to the use of the retrograde limb. In this procedure the vein is clamped with $2 \mathrm{~V}$ (venous) Acland clamps at its caudal and cranial ends in the second space and divided at its midpoint (Figure 9; step 3 ). The veins of the primary flap and secondary flaps are anastomosed anterograde and retrograde respectively using venous couplers (Figure 10). Some authors have advocated flushing the retrograde vein lumen with heparinized saline to identify any valves or resistance caused by obstruction. We do not believe this to be of any to be of practical significance. If the retrograde limb is not suitable then we consider an intraflap vascular arrangement by anastomosing the vein to the superior or inferior continuity.

There may be the rare occurrence in which the veins in both the second and third ICSs are inadequate. In this eventuality ETS anastomosis of the veins may be considered, although none of our cases required this option.

We would only use the TDVs in the axilla as a last resort. Their use would compromise any subsequent use of a salvage latissimus dorsi flap, make the flap inset difficult with anastomoses in two different anatomic locations and lead to lengthened surgical time due to second recipient vessel site exposure. Combined usage of 


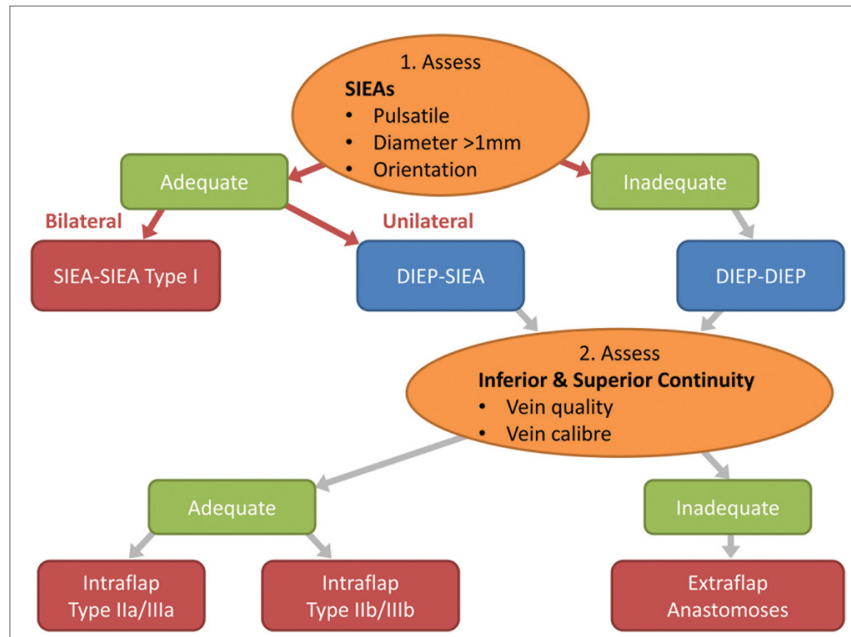

FIGURE 8 | Flow chart depicting the steps in decision making for the configuration of the flap vessels in abdominal double-pedicled free flap microvascular anastomoses.

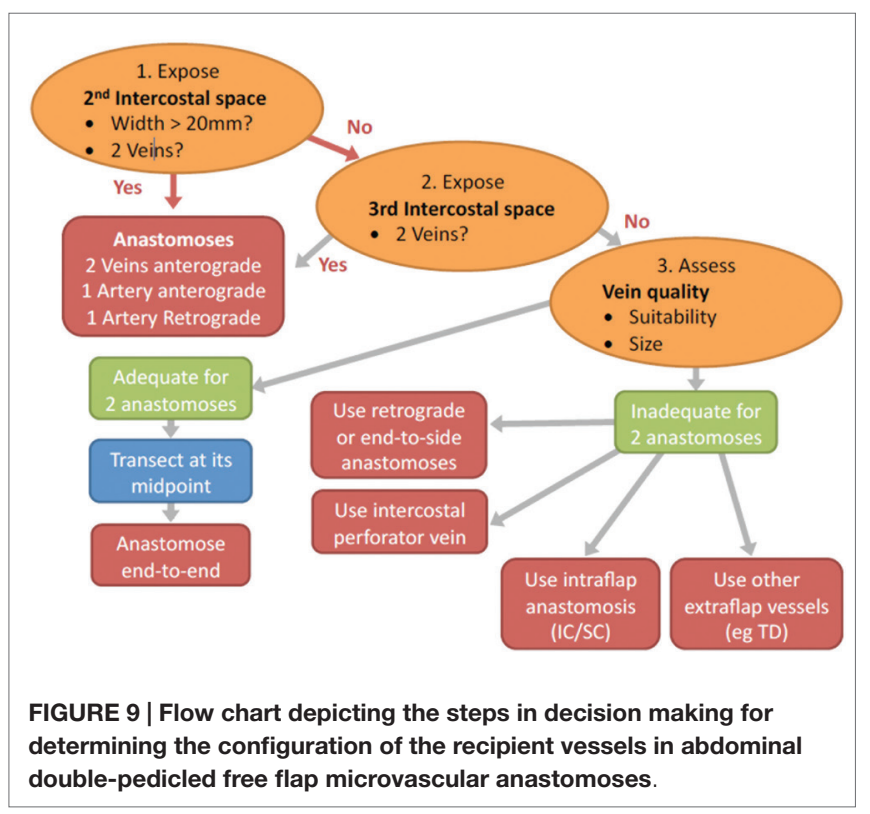

the IMVs and the TDVs for bipedicled anastomoses, however, becomes useful in chest wall reconstruction as the "flattened" flap adequately covers a wide chest defect. It is also easier to use the TDVs if the reconstruction is immediate with an associated axillary lymph node clearance. This exposes the vessels in advance, a key advantage of the subscapular-thoracodorsal system $(24,25)$.

To ensure good perfusion of the main flap, we perform the primary pedicle anastomosis first after exposing and evaluating the recipient vessels. This also reduces the risk of thrombosis at the secondary anastomoses. In contrast, $\mathrm{Xu}$ et al. and the Broomfield group carry out the intraflap anastomosis initially (7, 10). We prefer using a coupler for all our venous anastomoses as it is quick, technically easier and helps reduce flap ischemia time. After full flap perfusion, the flap can be inset in a coned, folded,

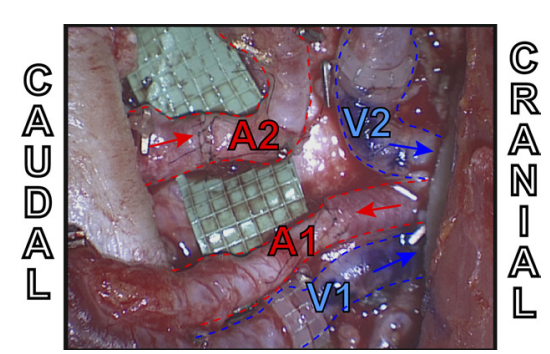

FIGURE 10 | Intraoperative example of extraflap DIEA-DIEA anastomoses to the internal mammary vessels using two anterograde veins (V1 and V2) both with venous couplers, one antegrade artery (A1) and one retrograde artery (A2).

TABLE 5 | The Malata-Rabey comprehensive classification of double pedicled abdominal free flap anastomoses.

\section{A. Intraflap anastomoses}

Type I SIEA - SIEA

Type II SIEA - DIEP

a. Inferior continuity

b. Superior continuity

c. Combination inferior and superior (vein and artery)

Type III DIEP - DIEP

a. Inferior continuity

b. Superior continuity

c. Combination of inferior and superior (vein and artery)

Type IV DIEP - DIEP Perforator (left or right)

a. Inferior continuity (unlikely unless centrally located and long IC)

b. Superior continuity

c. Combination of inferior and superior (artery and vein): highly unlikely

\section{Type V DIEP - DIEP}

a. End-to-side anastomosis (artery alone) (vein to vena comitans)

b. End-to-side anastomosis (artery and vein)

\section{B. Extra-flap anastomoses}

Type I To a single recipient site: IMVs

a. Flap 1 (both vessels antegrade); Flap 2 (artery retrograde, vein antegrade to second vc)

b. Flap 1 (both vessels antegrade); Flap 2 (both artery and vein retrograde)

Type II To a single recipient site: thoracodorsal system

a. Flap 1 (both vessels antegrade); Flap 2 (artery retrograde, vein antegrade to $\mathrm{vc}$ )

b. Flap 1 (both vessels antegrade); Flap 2 (both retrograde) - unlikely

Type III To two separate recipient sites

a. IMVs and subscapular-thoracodorsal system (preferably above serratus branch)

b. IMVs and pectoral vessels (unlikely)

c. IMVs and other vessels (cephalic vein loop, etc) - when in "trouble"

\section{Combined intraflap and extra-flap anastomoses}

stacked, or adjacent arrangement taking great care not to disrupt the anastomoses. When folding the flap we place the flexure inferiorly in order to give the best esthetic appearance, but it can be made superiorly depending on the breast projection desired.

The disadvantages of bipedicled free flaps are their technical complexity, difficulty in flap inset and shaping, tightness of 
the abdominal closure, prolonged surgical duration and cost. However, we believe that by considering the crucial factors discussed above the surgeon can minimize the donor site morbidity, reduce the duration of flap harvest and vessel anastomosis and optimize the ease of flap inset. From our experience we have proposed a treatment algorithm in Figures $\mathbf{8}$ and $\mathbf{9}$ and a comprehensive classification of bipedicled free flap abdominal reconstructions (Table 5; Figure 7).

\section{Conclusion}

Bipedicled free flaps can sometimes be necessary in patients undergoing abdominal flap breast reconstruction and can be

\section{References}

1. Hartrampf CR, Scheflan M, Black PW. Breast reconstruction with a transverse abdominal island flap. Plast Reconstr Surg (1982) 69(2):216-25. doi:10.1097/00006534-198202000-00006

2. Holm C, Mayr M, Hofter E, Ninkovic M. Perfusion zones of the DIEP flap revisited: a clinical study. Plast Reconstr Surg (2006) 117(1):37-43. doi:10.1097/01.prs.0000185867.84172.c0

3. Arnez ZM, Scamp T. The bipedicled free TRAM flap. Br J Plast Surg (1992) 45(3):214-8. doi:10.1016/0007-1226(92)90080-H

4. Blondeel PN, Boeckx WD. Refinements in free flap breast reconstruction: the free bilateral deep inferior epigastric perforator flap anastomosed to the internal mammary artery. Br J Plast Surg (1994) 47(7):495-501. doi:10.1016/0007-1226(94)90033-7

5. Agarwal JP, Gottlieb LJ. Double pedicle deep inferior epigastric perforator/ muscle-sparing TRAM flaps for unilateral breast reconstruction. Ann Plast Surg (2007) 58(4):359-63. doi:10.1097/01.sap.0000239818.28900.81

6. Hamdi M, Khuthaila DK, Van Landuyt K, Roche N, Monstrey S. Doublepedicle abdominal perforator free flaps for unilateral breast reconstruction: new horizons in microsurgical tissue transfer to the breast. J Plast Reconstr Aesthet Surg (2007) 60(8):904-12;discussion13-4. doi:10.1016/j. bjps.2007.02.016

7. Xu H, Dong J, Wang T. Bipedicle deep inferior epigastric perforator flap for unilateral breast reconstruction: seven years' experience. Plast Reconstr Surg (2009) 124(6):1797-807. doi:10.1097/PRS.0b013e3181bf81cf

8. Beahm EK, Walton RL. The efficacy of bilateral lower abdominal free flaps for unilateral breast reconstruction. Plast Reconstr Surg (2007) 120(1):41-54. doi:10.1097/01.prs.0000263729.26936.31

9. Ali RS, Garrido A, Ramakrishnan V. Stacked free hemi-DIEP flaps: a method of autologous breast reconstruction in a patient with midline abdominal scarring. Br J Plast Surg (2002) 55(4):351-3. doi:10.1054/bjps.2002.3834

10. Figus A, Fioramonti P, Ramakrishnan V. Stacked free SIEA/DIEP flap for unilateral breast reconstruction in a thin patient with an abdominal vertical midline scar. J Reconstr Microsurg (2007) 23(8):523-5. doi:10.105 5/s-2007-1022692

11. Schoeller T, Wechselberger G, Roger J, Hussl H, Huemer GM. Management of infraumbilical vertical scars in DIEP-flaps by crossover anastomosis. J Plast Reconstr Aesthet Surg (2007) 60(5):524-8.

12. Chan RK, Przylecki W, Guo L, Caterson SA. Case report. The use of both antegrade and retrograde internal mammary vessels in a folded, stacked deep inferior epigastric artery perforator flap. Eplasty (2010) 10:e32.

13. DellaCroce FJ, Sullivan SK, Trahan C. Stacked deep inferior epigastric perforator flap breast reconstruction: a review of 110 flaps in 55 cases over 3 years. Plast Reconstr Aesthet Surg (2011) 127(3):1093-9.

14. Rabey NG, Erel E, Malata CM. Double-pedicled abdominal free flap using an entirely new microvascular combination of DIEP and SIEA vascular pedicles for unilateral breast reconstruction: a novel addition to the Hamdi classification. Plast Reconstr Surg (2012) 130(5):767e-9e. doi:10.1097/ PRS.0b013e318267d995

15. Mohan AT, Patel NG, Malata CM. Combination of the superior and inferior pedicle "continuities" for anastomosis of an SIEA flap to a contralateral DIEP successfully undertaken in large microvascular surgery centers. They are a reliable and safe option for unilateral autologous breast reconstruction when the volume of tissue required to make a breast mound is larger than that can be transferred on a single flap pedicle. They can greatly benefit the correct patient.

There are numerous techniques for the microsurgical constructs of bipedicled flaps and surgeons intending to perform this surgery should be familiar with them. Our series shows that double-pedicled abdominal free flaps can be safely undertaken with total rib-preservation technique of internal mammary vessel exposure. The algorithm that we have derived from our experience can assist surgeons embarking on this complex microsurgery if they adopt the discussed principles.

flap in double-pedicled abdominal free flaps: a further modification of the Hamdi classification. J Plast Reconstr Aesthet Surg (2014) 67(10):e237-9. doi:10.1016/j.bjps.2014.06.008

16. Li S, Mu L, Li Y, Xu J, Yang M, Zhao Z, et al. Breast reconstruction with the free bipedicled inferior TRAM flap by anastomosis to the proximal and distal ends of the internal mammary vessels. J Reconstr Microsurg (2002) 18(3):161-8. doi:10.1055/s-2002-28498

17. Ng RL, Youssef A, Kronowitz SJ, Lipa JE, Potochny J, Reece GP. Technical variations of the bipedicled TRAM flap in unilateral breast reconstruction: effects of conventional versus microsurgical techniques of pedicle transfer on complications rates. Plast Reconstr Surg (2004) 114(2):374-84;discussion85-8. doi:10.1097/01.PRS.0000131879.34814.8A

18. Malata CM, Moses M, Mickute Z, Di Candia M. Tips for successful microvascular abdominal flap breast reconstruction utilizing the "total rib preservation" technique for internal mammary vessel exposure. Ann Plast Surg (2011) 66(1):36-42. doi:10.1097/SAP.0b013e3181e19daf

19. Agarwal JP, Ley E, Tieman J. Salvage of SIEA flaps using the retrograde internal mammary system. Microsurgery (2010) 30(7):545-8. doi:10.1002/micr.20791

20. Salgarello M, Visconti G, Barone-Adesi L, Cina A. The retrograde limb of internal mammary vessels as reliable recipient vessels in DIEP flap breast reconstruction: a clinical and radiological study. Ann Plast Surg (2013) 74(4):447-53. doi:10.1097/SAP.0b013e31829fd2e3

21. Mackey SP, Ramsey KW. Exploring the myth of the valveless internal mammary vein - a cadaveric study. J Plast Reconstr Aesthet Surg (2011) 64(9):1174-9. doi:10.1016/j.bjps.2011.03.045

22. Arnez ZM, Valdatta L, Tyler MP, Planinsek F. Anatomy of the internal mammary veins and their use in free TRAM flap breast reconstruction. Br J Plast Surg (1995) 48(8):540-5. doi:10.1016/0007-1226(95)90041-1

23. Clark CP III, Rohrich RJ, Copit S, Pittman CE, Robinson J. An anatomic study of the internal mammary veins: clinical implications for free-tissue-transfer breast reconstruction. Plast Reconstr Surg (1997) 99(2):400-4. doi:10.1097/00006534-199702000-00014

24. Moran SL, Nava G, Behnam AB, Serletti JM. An outcome analysis comparing the thoracodorsal and internal mammary vessels as recipient sites for microvascular breast reconstruction: a prospective study of 100 patients. Plast Reconstr Surg (2003) 111(6):1876-82. doi:10.1097/01.PRS.0000056872.06003.7E

25. Pradas-Irun C, Azzawi K, Malata CM. A plea for recipient vascular pedicle versatility in microvascular breast reconstruction: the conundrum of absent internal mammary veins. Plast Reconstr Surg (2012) 129(2):383e-5e. doi:10.1097/PRS.0b013e31823aeec2

Conflict of Interest Statement: The authors declare that the research was conducted in the absence of any commercial or financial relationships that could be construed as a potential conflict of interest.

Copyright (C) 2015 Malata and Rabey. This is an open-access article distributed under the terms of the Creative Commons Attribution License (CC BY). The use, distribution or reproduction in other forums is permitted, provided the original author(s) or licensor are credited and that the original publication in this journal is cited, in accordance with accepted academic practice. No use, distribution or reproduction is permitted which does not comply with these terms. 